\title{
Influência da Refusão por Plasma na Microestrutura de um Revestimento Fe-Mn-Cr-Si Depositado por Aspersão Térmica Arco Elétrico sobre Aço Inoxidável ASTM A743-CA6NM
}

\author{
(Influence of Plasma Remelting on the Microstructure of Fe-Mn-Cr-Si Arc thermal spray Coating Deposited on ASTM A743- \\ CA6NM Stainless Steel)
}

\begin{abstract}
Anderson Geraldo Marenda Pukasiewicz ${ }^{(1)}$, Fernando Ratti de Oliveira ${ }^{(2)}$, André Ricardo Capra ${ }^{(3)}$, Ramón Sigifredo Cortés Paredes ${ }^{(4)}$
${ }^{1}$ UTFPR, Universidade Tecnológica Federal do Paraná, Campus Ponta Grossa, Coordenação de Mecânica, Ponta Grossa, Paraná, Brasil anderson@utfpr.edu.br

${ }^{2}$ Aluno de Graduação da UTFPR, Universidade Tecnológica Federal do Paraná, Campus Ponta Grossa, Engenharia Mecânica, Ponta Grossa, Paraná, Brasil fernando_piu@hotmail.com

${ }^{3}$ LACTEC, Instituto de Tecnologia para o Desenvolvimento, Curitiba, Paraná, Brasil, andre.capra@lactec.org.br

${ }^{4}$ UFPR, Universidade Federal do Paraná, Departamento de Mecânica, Curitiba, Paraná, Brasil, ramon@ufpr.br
\end{abstract}

\section{Resumo}

ASTM A743-CA6NM é um aço inoxidável martensítico muito utilizado na fabricação de turbinas hidráulicas devido a sua elevada tenacidade, entretanto apresenta restrições com relação à regiões recuperadas por soldagem. Diferentes técnicas de deposição tem sido aplicadas com o intuito de reduzir ou eliminar a tensão residual. A deposição de revestimentos resistentes a cavitação é outra forma importante de aumentar a vida útil destes componentes. O objetivo deste trabalho é avaliar a influência do tipo e intensidade de corrente de refusão por plasma na microestrutura, composição química e microdureza de um revestimento $\mathrm{Fe}-\mathrm{Mn}$-Cr-Si resistente a cavitação depositado por aspersão térmica arco elétrico sobre aço ASTMA743-CA6NM. Observou-se que a adoção de menores valores de corrente média, assim como a utilização de corrente pulsada reduziram a formação de ferrita $\delta$ e a espessura final da ZTA, possibilitando a formação do revestimento com menores alterações na microestrutura do metal base. Verificou-se que a microestrutura e microdureza dos revestimentos refundidos não se mostraram muito sensivel a variações na diluição do metal base. A utilização de corrente contínua promoveu um alinhamento da estrutura dendrítica no sentido da movimentação da tocha, entretanto este comportamento não foi observado em revestimentos refundidos com corrente pulsada.

Palavras-chave: Zona termicamente afetada; Aço inoxidável martensítico; Formação de liga superficial.

Abstract: ASTM A743-CA6NM martensitic stainless steel have been used in hydraulic turbines manufacturing, but show some restrictions in welded recovered areas. Different techniques have been applied in order to reduce or eliminate residual stress, with life increase. The deposition of cavitation resistant coatings is another important way to increase the service life of these components. The objective of this study is evaluate the influence of type and intensity of plasma remelting current on the microstructure, chemical composition and microhardness of the Fe-Cr-Mn-Si cavitation resistant coatings deposited by arc thermal spray process on CA6NM steel. It was observed that lower level of current, as well as, the use of pulsed current reduce ferrite $\delta$ layer and HAZ thickness, reducing base metal modifications during coating remelting. It was observed that base metal dilution alterations did not promote any significant modification on microstructure and microhardness of the remelted coatings. Constant arc remelting current promoted a microstructure alignment with plasma torch dislocation, this behavior was not observed in pulsed current remelted coatings.

Key-words: Heat affected zone; Martensitic stainless steel; Surface alloying.

\section{Introdução}

Turbinas hidráulicas são estruturas metálicas capazes de transformar a energia potencial e cinética da água de um rio, ou reservatório, em energia elétrica. Um dos principais problemas de manutenção encontrados nos rotores de turbinas hidráulicas

(Recebido em 07/03/2012; Texto final em 20/03/2012).

Artigo originalmente publicado no CONSOLDA 2011 é a perda de massa por cavitação, assim como a presença de trincas. O processo de cavitação varia de intensidade, em função do perfil hidráulico e regime de operação empregado, enquanto que as trincas podem ser inicialmente oriundas de defeitos de soldagem ou fundição, assim como provenientes da operação normal do equipamento, que ocasionam a formação e crescimento de trincas por diferentes mecanismos de fadiga de baixo e alto ciclos [1].

A erosão por cavitação ocorre quando, num fluxo líquido, formam-se bolhas de vapor que colidem contra a superfície metálica, liberando energia e promovendo a perda de massa na 
superfície do componente. A cavitação em turbinas hidráulicas é gerada principalmente pela diferença de pressão da água existente ao longo das pás, provenientes da variação do fluxo de água sobre as mesmas. A perda de massa, assim como o processo de reparo fazem com que as superfícies das pás percam o perfil original, podendo agravar o fenômeno de cavitação.

O reparo das áreas cavitadas é realizado principalmente por soldagem MIG/MAG metal inert/active gas, depositando-se aços inoxidáveis austeníticos, ou ligas inoxidáveis austeníticas com cobalto [2,3]. Além destas ligas tem-se pesquisado a utilização de ligas como NiTi e ligas Fe-Mn-Cr-Si para a produção de peças e revestimentos resistentes à cavitação [4-11]. Estes materiais apresentam elevada tenacidade, que combinada com o elevado endurecimento por encruamento e formação de martensita sob solicitação mecânica, conferem a estes materiais uma elevada resistência à cavitação.

Turbinas hidráulicas são normalmente produzidas em aço-C e aço inoxidável martensítico macio. Em geral, as turbinas fabricadas em aço inoxidável martensítico macio apresentam menor perda de massa por cavitação, porém apresentam maiores limitações quanto ao reparo por soldagem de regiões cavitadas, ou com presença de trinca. $\mathrm{O}$ reparo por soldagem de aços inoxidáveis martensíticos macios é mais crítico, devido principalmente a formação de ferrita $\delta$ e à baixa tenacidade da união soldada e ZTA, zona termicamente afetada. A maior redução da tenacidade na ZTA ocorre na zona termicamente afetada de granulação grosseira, ZTAGG, pela precipitação de ferrita $\delta$ [12]. Na Figura 1 é possível visualizar o diagrama de equilíbrio e as diferentes regiões da ZTA de um aço martensítico macio.
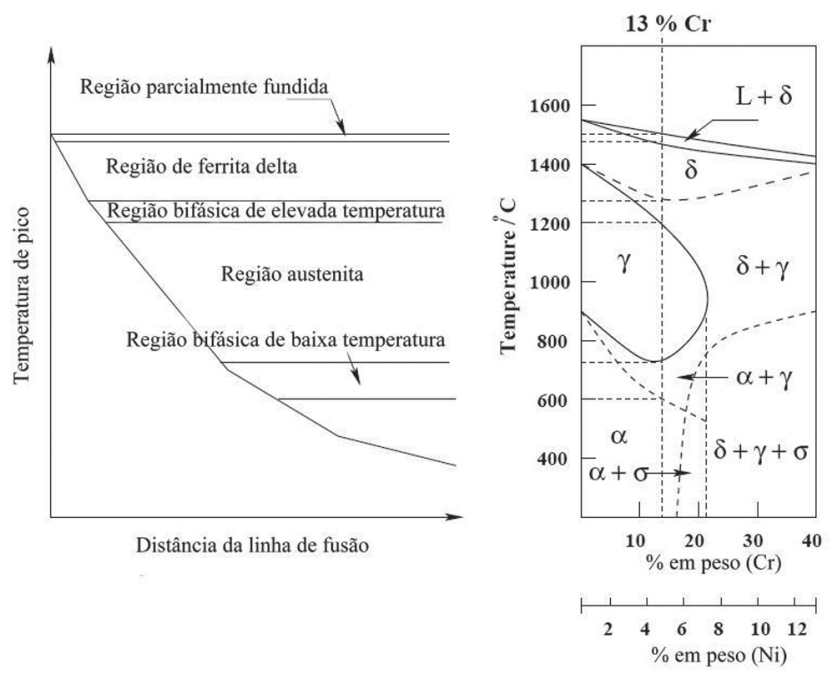

Figura 1. Diagrama esquemático mostrando a ZTA de um aço inoxidável martensítico macio (adaptado de [13]).

Com o intuito de reduzir os níveis de tensões residuais, buscando adicionalmente elevar a tenacidade após processo de recuperação por soldagem, tem-se pesquisado processos de deposição de revestimentos com a indução de baixas, ou até nenhuma tensão residual, aliado a ciclos térmicos de baixa temperatura, como por exemplo, o processo de aspersão térmica.
No processo de deposição ASP, o arco voltaico funde o metal, que é continuamente alimentado pelos arames, sendo então destacado e projetado pelo ar-comprimido, ou gás inerte sob alta pressão, em direção ao substrato, formando uma microestrutura contendo fase metálica, óxidos e poros. O reparo de superfícies cavitadas por aspersão térmica foi considerado viável para reparos de superfícies onde a cavitação apresentouse menos severa e com uma menor espessura erodida, obtendo custos 3 vezes inferiores ao do mesmo trabalho realizado por soldagem, e com um tempo de aplicação menor [14]. Entretanto a presença de óxidos altera significativamente as propriedades do revestimento aspergido em relação aos materiais uniformes, reduzindo a resistência a cavitação de revestimentos aspergidos em relação a revestimentos soldados [14]. A presença de óxidos reduz a ductilidade, tenacidade, soldabilidade e conformabilidade dos revestimentos, assim como afeta as transformações de fase, tensões residuais e propriedades mecânicas do revestimento [15$16]$.

Diversas procedimentos de refusão têm sido aplicados para alterar a camada depositada por aspersão térmica, uma das finalidades é a de eliminar a presença dos óxidos interlamelares e poros, assim como permitir uma melhora na aderência do revestimento ao substrato, promovendo união metalúrgica $\mathrm{e}$ melhorando as propriedades à cavitação significativamente, possibilitando o uso da técnica de deposição por aspersão para regiões que sofreram um processo de cavitação mais severo [8,9,11,17-21]. O uso da técnica de aspersão térmica seguido de refusão permite obter revestimentos com a utilização de uma maior variedade de materiais ou ligas a serem aplicadas, como por exemplo, ligas que apresentariam maiores dificuldades de serem depositadas por técnicas de soldagem convencionais como MIG/MAG [11].

Pela refusão, observa-se também que os parâmetros de refusão são muito importantes para as propriedades obtidas. Hiraga, et al., 1999 estudaram o comportamento à cavitação de revestimentos NiTi, depositados por aspersão a plasma spray, e refundidos por laser sobre substratos de Ti6Al4V. Estes autores observaram que maiores densidades de energia promoveram uma maior resistência à cavitação devido a maior homogeneidade química obtida com o aumento na energia do processo de refusão por laser [21].

O principal objetivo deste trabalho é avaliar as alterações provocadas pela utilização de corrente contínua e pulsada, assim como da utilização de diferentes níveis de intensidade de corrente média na microestrutura de um revestimento Fe$\mathrm{Mn}-\mathrm{Cr}-\mathrm{Si}$ depositado por aspersão térmica arco elétrico e refundido por plasma de arco transferido PTA. Adicionalmente serão avaliadas as alterações na microestrutura e microdureza da ZTA do metal base ASTM A-743 CA6NM com as modificações destes parâmetros.

\section{Materiais e Métodos}

\subsection{Preparação dos arames tubulares}

As ligas a serem depositadas foram preparadas na forma de arames tubulares com 1,6mm de diâmetro, do tipo "metal 
Tabela 1. Composição da fita e pós metálicos utilizados (percentagem em peso).

\begin{tabular}{|l|c|c|c|c|c|c|c|c|c|}
\hline & $\% \mathrm{Fe}$ & $\% \mathrm{C}$ & $\% \mathrm{~N}$ & $\% \mathrm{Mn}$ & $\% \mathrm{Cr}$ & $\% \mathrm{Si}$ & $\% \mathrm{Ni}$ & $\% \mathrm{Al}$ & $\% \mathrm{Ti}$ \\
\hline Fita aço-C & 99,65 & 0,05 & & 0,30 & & & & & \\
\hline $\mathrm{Fe}$ & 99,65 & 0,10 & & 0,05 & & 0,20 & & & \\
\hline $\mathrm{Mn}$ & 0,10 & 0,01 & & 99,18 & & 0,03 & & & \\
\hline $\mathrm{Cr}$ & 0,14 & & & & 99,44 & 0,11 & & 0,05 & \\
\hline $\mathrm{Fe}-\mathrm{Cr}-\mathrm{N}$ & 35,04 & 0,10 & 5,20 & & 63,00 & 0,80 & & & \\
\hline Fe-Mn & 19,57 & 1,50 & & 76,70 & & 2,60 & & & \\
\hline $\mathrm{Si}$ & 0,02 & 0,04 & & 0,04 & & 99,10 & & 0,17 & 0,02 \\
\hline
\end{tabular}

Tabela 2. Composição final estimada do arame tubular e metal base CA6NM.

\begin{tabular}{|c|c|c|c|c|c|c|c|c|}
\hline Liga & $\% \mathrm{Fe}$ & $\% \mathrm{~N}$ & $\% \mathrm{C}$ & $\% \mathrm{Mn}$ & $\% \mathrm{Cr}$ & $\% \mathrm{Si}$ & $\% \mathrm{Ni}$ & $\% \mathrm{Mo}$ \\
\hline SMA_Mn1 & res. & 0,20 & 0,16 & 20,09 & 8,27 & 4,50 & 0,00 & 0,00 \\
\hline ASTM A743-CA6NM & res & 0,00 & 0,024 & 1,00 & 13,7 & 1,00 & 3,9 & 0,36 \\
\hline
\end{tabular}

Tabela 3. Condições de jateamento dos corpos de prova a serem revestidos.

\begin{tabular}{|l|l|}
\hline Parâmetro & Valores empregados \\
\hline Abrasivo & Óxido de alumínio branco \#36mesh \\
\hline Tipo de jato empregado & Jato por pressão \\
\hline Pressão de jateamento & $80-90 \mathrm{psi}$ \\
\hline Distância de jateamento & $120-150 \mathrm{~mm}$ \\
\hline Rugosidade mínima obtida & $4,0 \mu \mathrm{m} \mathrm{Ra}$ \\
\hline
\end{tabular}

Tabela 4 Parâmetros ASP utilizados na deposição do revestimento.

\begin{tabular}{|c|c|}
\hline Parâmetro & Valores empregados \\
\hline Corrente $(\mathrm{A})$ & 180 \\
\hline Tensão $(\mathrm{V})$ & 30 \\
\hline Pressão do ar-comprimido $(\mathrm{kPa})$ & 410 \\
\hline Gás de transporte & Ar-comprimido \\
\hline Distância pistola-peça $(\mathrm{mm})$ & 120 \\
\hline Espessura dos revestimentos $(\mu \mathrm{m})$ & $1000 \pm 100$ \\
\hline
\end{tabular}

Tabela 5. Parâmetros de refusão por plasma utilizados na liga Fe-MnCr-Si.

\begin{tabular}{|c|c|c|c|c|c|c|c|}
\hline $\begin{array}{c}\text { Corrente } \\
(\mathrm{A})\end{array}$ & $\begin{array}{c}\text { Corrente } \\
\text { média (A) }\end{array}$ & $\begin{array}{c}\mathrm{T}_{\mathrm{p}} / \mathrm{T}_{\mathrm{b}}{ }^{*} \\
(\mathrm{~s})\end{array}$ & $\begin{array}{c}\mathrm{DBP} * * \\
(\mathrm{~mm})\end{array}$ & $\begin{array}{c}\text { Recuo do } \\
\text { eletrodo }(\mathrm{mm})\end{array}$ & $\begin{array}{c}\text { Vazão de gás de } \\
\text { Plasma (Ar) } \\
(1 / \mathrm{min})\end{array}$ & $\begin{array}{c}\text { Vazão de gás de } \\
\text { Proteção } \\
\left(\mathrm{Ar} 3 \% \mathrm{CO}_{2}\right)(1 / \mathrm{min})\end{array}$ & $\begin{array}{c}\text { Velocidade de } \\
\text { refusão (cm/min) }\end{array}$ \\
\hline $180-80$ & 130 & $0,1 / 0,1$ & 7,0 & 0,8 & 1,1 & 12,0 & 10,0 \\
\hline $140-80$ & 110 & $0,1 / 0,1$ & 7,0 & 0,8 & 1,1 & 12,0 & 10,0 \\
\hline $100-80$ & 90 & $0,1 / 0,1$ & 7,0 & 0,8 & 1,1 & 12,0 & 10,0 \\
\hline 130 & 130 & - & 7,0 & 0,8 & 1,1 & 1,0 & 10,0 \\
\hline 110 & 110 & - & 7,0 & 0,8 & 1,1 & 12,0 & 10,0 \\
\hline 90 & 90 & - & 7,0 & 0,8 & 1,1 & 12,0 \\
\hline
\end{tabular}

Tabela 6. Formulações e procedimentos utilizados na revelação da microestrutura [12].

\begin{tabular}{|l|l|l|l|}
\hline Reativo & Composição & Método & Objetivo \\
\hline Villela & $\begin{array}{l}1 \mathrm{~g} \mathrm{C}_{4} \mathrm{H}_{3} \mathrm{OH}\left(\mathrm{NO}_{2}\right)_{3} \\
5 \mathrm{ml} \mathrm{HCl} \\
100 \mathrm{ml} \mathrm{C}_{2} \mathrm{H}_{6} \mathrm{OH}\end{array}$ & $\begin{array}{l}\text { Imersão da amostra } \\
\text { por } 60 \mathrm{~s}\end{array}$ & Revela martensita. \\
\hline Sulfúrico & $\begin{array}{l}20 \mathrm{ml} \mathrm{H}_{2} \mathrm{SO}_{4} \\
0.01 \mathrm{~N} \mathrm{NH}_{4} \mathrm{CNS} \\
80 \mathrm{ml} \mathrm{H}_{2} \mathrm{O}\end{array}$ & $\begin{array}{l}\text { Ataque eletrolítico a 4 v } \\
\text { por 20 s. }\end{array}$ & $\begin{array}{l}\text { Revela ferrita-delta } \\
\text { mas não martensita. }\end{array}$ \\
\hline
\end{tabular}


cored", ou seja, utilizando-se apenas elementos metálicos em seu interior. Os arames foram preparados utilizando-se uma fita de aço-C, preenchida com pós metálicos contendo os elementos de liga: cromo $(\mathrm{Cr})$, manganês $(\mathrm{Mn})$, silício $(\mathrm{Si})$, níquel $(\mathrm{Ni})$, carbono $(\mathrm{C})$, nitrogênio $(\mathrm{N})$ e ferro $(\mathrm{Fe})$, Tabela 1, obtendo a composição química planejada, Tabela 2 , onde também pode ser visualizado a composição química do metal base.

Antes da preparação dos arames, os pós metálicos foram misturados em um misturador do tipo "Y" por 30 minutos, após mistura mecânica, os pós foram novamente homogeneizados e adicionados a fita de aço-C. Durante o processo de manufatura do arame, este é conformado na forma de um tubo, e depois estirado, fornecendo uma relação fita/recheio adequada à composição planejada, neste caso $60 \%$ em peso de fita e $40 \%$ de recheio metálico. Após o estiramento, a fita é trefilada e rebobinada.

\subsection{Deposição por aspersão térmica arco elétrico}

Para a deposição dos revestimentos foram preparados substratos de aço inoxidável martensítico macio ASTM A743CA6NM, com dimensões de $25 \times 50 \times 75 \mathrm{~mm}$ (espessura $\times$ largura $\mathrm{x}$ comprimento). Após a confecção das amostras, estas foram previamente preparadas através de jateamento abrasivo, Tabela 3. As medições de rugosidade foram realizadas através de um rugosímetro portátil, com apalpador de contato mecânico, marca Mitutoyo, modelo SJ201, com capacidade de medição entre 0,05 e $15 \mu \mathrm{m}$ Ra.

Para o processo de deposição da liga em estudo utilizouse aspersão térmica a arco (ASP), sendo a deposição realizada com o auxílio de uma fonte elétrica e uma pistola de aspersão a arco elétrico, com um ângulo de deposição de $90^{\circ}$ em relação à superfície procurando-se estabelecer uma espessura média de $100 \mu \mathrm{m}$ por camada depositada. Os parâmetros de deposição utilizados são visualizados na Tabela 4 .

\subsection{Refusão do revestimento aspergido}

Neste trabalho utilizou-se a técnica de refusão por plasma

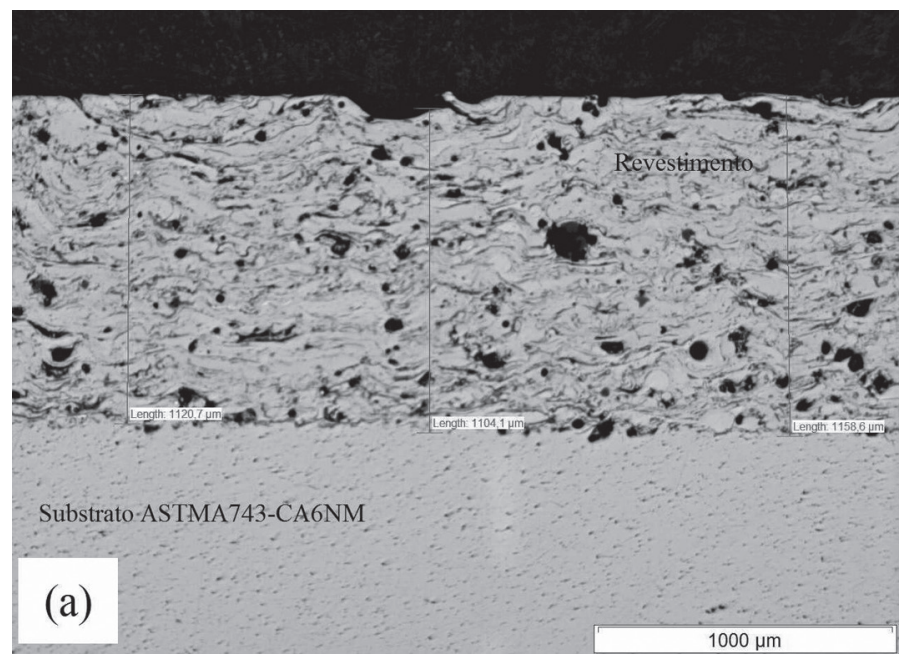

de arco transferido (PTA- plasma transferred arc), Tabela 5. O equipamento utilizado foi uma fonte de soldagem multiprocesso e uma tocha de plasma PTA refrigerada, acoplada a um sistema automatizado de deslocamento. Para o processo de preparação dos corpos de prova utilizaram-se os substratos de aço ASTM A743-CA6NM previamente depositados.

Após inspeção visual as amostras depositadas por ASP e refundidas por plasma PTA foram preparadas para caracterização metalográfica através de equipamento automatizado de corte. As etapas de lixamento e polimento foram realizadas de forma automatizada, com força de lixamento de $20 \mathrm{~N}$ e de polimento de $15 N$. Foram utilizadas lixas 220, 320, 400, 600 e 1200 mesh de carboneto de silício, seguido de polimento com suspensão de diamante $3,0 \mu \mathrm{m}$ e $0,25 \mu \mathrm{m}$ e sílica coloidal com $0,04 \mu \mathrm{m}$. Para revelação da microestrutura foram utilizados reativos Vilella e ácido sulfúrico eletrolítico, Tabela 6.

A caracterização metalográfica foi realizada em um microscópio OlympusBX60, com a aquisição de imagens por meio de software, Analysis 5,1, enquanto que a microscopia electrónica foi realizada em um microscópio Philips XL30 contendo sistema de análise de composição química por EDX. Adicionalmente foi avaliado o perfil de microdureza através de um equipamento Time Vickers com aplicação de carga de 300 gf.

Os ciclos térmicos foram obtidos com o auxilio de um sistema de aquisição de dados PXI da National Instruments e software LabView Signal Express com aquisição de sinais a cada $0,25 \mathrm{~ms}$. Para a definição dos ciclos térmicos originados somente o passe central foi analisado. Os termopares do tipo K utilizados foram fixados no centro da peça a $25 \mathrm{~mm}$ de profundidade com uma distância de 3,7 e $11 \mathrm{~mm}$ da superfície refundida.

\section{Resultados e Discussão}

\subsection{Aspecto geral e da microestrutura do revestimento aspergido}

A espessura e microestrutura do revestimento aspergido são observadas na Figura 2(a) e (b). A microestrutura ASP é

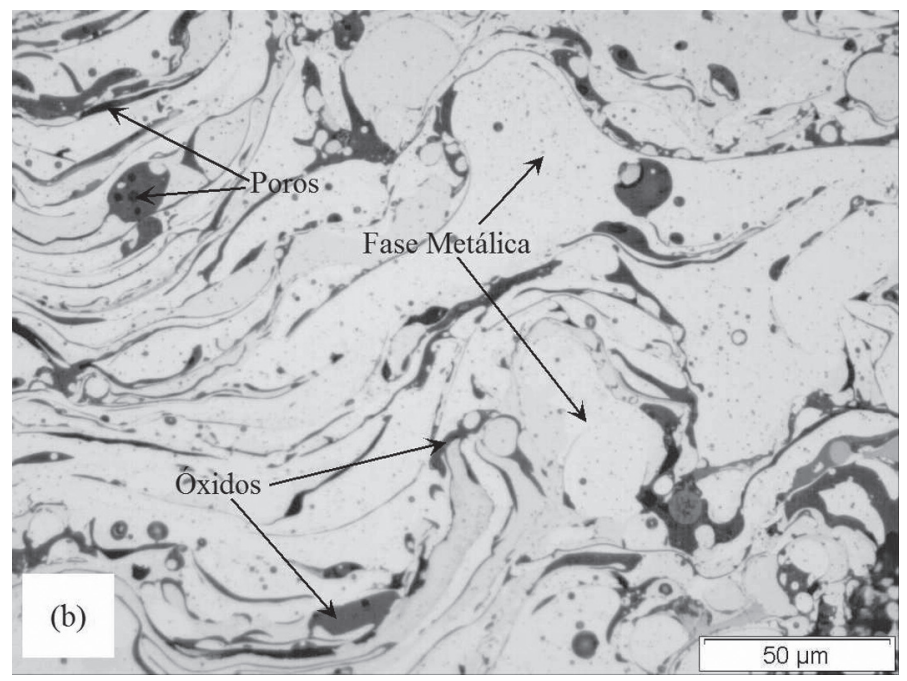

Figura 2. Microestrutura do revestimento aspergido, (a) espessura do revestimento 100x, (b) óxidos, poros e fase metálica. 
composta de poros (áreas pretas), óxidos formados durante o processo de deposição (áreas cinza escuro) e fase metálica (áreas cinza claro). A proporção de poros nas amostras foi de $1,1 \pm 0,9 \%$ de poros, $18,2 \pm 5,0 \%$ de óxidos e $80,7 \pm 5 \%$ de fase metálica. A composição química em peso, determinada por EDX, do revestimento depositado é de 13,02 $\pm 2,8 \% \mathrm{Mn}, 6,8 \pm 1,2$ $\mathrm{Cr}, 3,78 \pm 0,39 \mathrm{Si}, 0,13 \% \mathrm{C}$ e $0,23 \% \mathrm{~N}$, ocorrendo perda parcial dos elementos desoxidantes $\mathrm{Mn}, \mathrm{Cr}$ e $\mathrm{Si}$.

Os revestimentos depositados por aspersão térmica

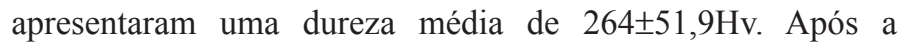
deposição os substratos de aço CA6NM não apresentaram alterações significativas na microestrutura e microdureza devido as baixas temperaturas induzidas no metal base durante a deposição. Temperaturas máximas de $204 \pm 15^{\circ} \mathrm{C}$ foram observadas, à $3 \mathrm{~mm}$ da superfície depositada, enquanto que as temperaturas máximas a 7 e $11 \mathrm{~mm}$ da superfície foram de $150 \pm 19$ e $118 \pm 12^{\circ} \mathrm{C}$ respectivamente.

\subsection{Avaliação da microestrutura e microdureza dos revestimentos refundidos}

Na Figura 3 pode-se observar a seção transversal de algumas amostras refundidas, nestas imagens observa-se que a utilização

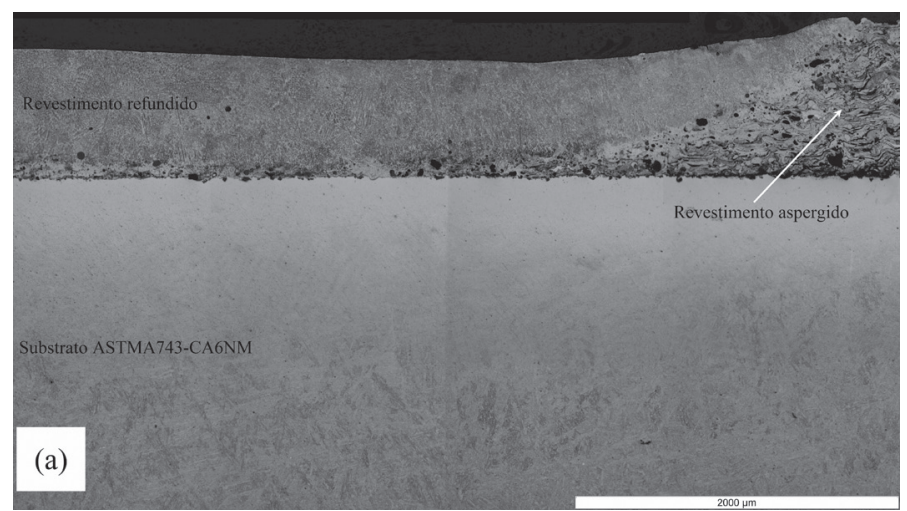

de corrente pulsada de 100-80A não promoveu diluição do metal de base. Fato semelhante foi observado nas amostras refundidas com 90A e 110A mesmo utilizando sobreposição de 50\% entre os cordões, enquanto que as amostras refundidas com correntes de $130 \mathrm{~A}$ e corrente pulsada de $140-80$ e 180-80A apresentaram fusão completa do metal base. Os valores de penetração no metal base alcançados nas amostras de $130 \mathrm{~A}$ foram de $300 \mu \mathrm{m}$ na região mais profunda, $170 \mu \mathrm{m}$ para as amostras refundidas com $140-80 \mathrm{~A}$ de corrente e de $800 \mu \mathrm{m}$ para as amostras refundidas com corrente de $180-80 \mathrm{~A}$.

Em função do processo de flotação dos óxidos durante a refusão, os revestimentos apresentaram uma redução na espessura final em relação aos revestimentos aspergidos, como pode ser observado mais claramente na amostra 100-80A, Figura 3(a). A redução na espessura dos revestimentos, entre 20 e $30 \%$ aproximadamente, é próxima à porcentagem em área somada de poros e óxidos presente nos revestimentos aspergidos.

A liga Fe-Mn-Cr-Si após refusão apresentou estrutura dendrítica, como observado na Figura 4(a). Nas amostras com corrente contínua houve um direcionamento da estrutura dendrítica, na direção da movimentação da tocha, Figura 4(a). A orientação na formação da estrutura dendrítica foi alterada com o uso de corrente pulsada, notadamente nas amostras 140 e 180-

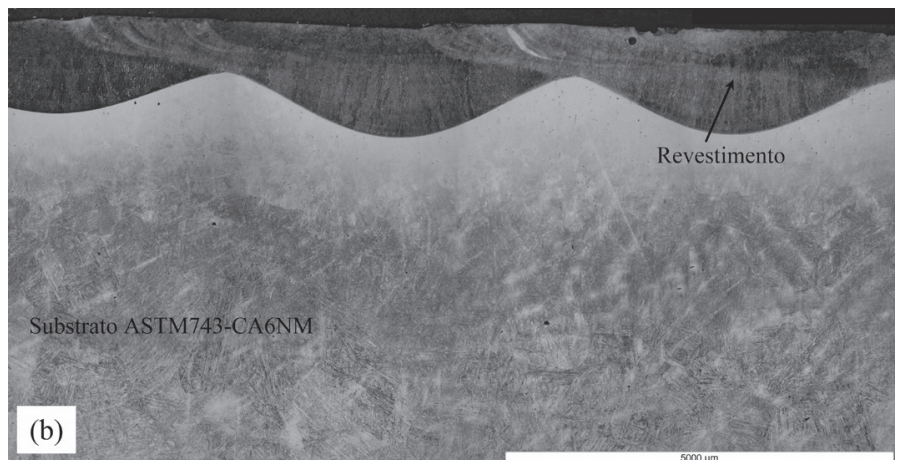

Figura 3. Perfil transversal das amostras após refusão (a) 100-80 e (b) 180-80A.
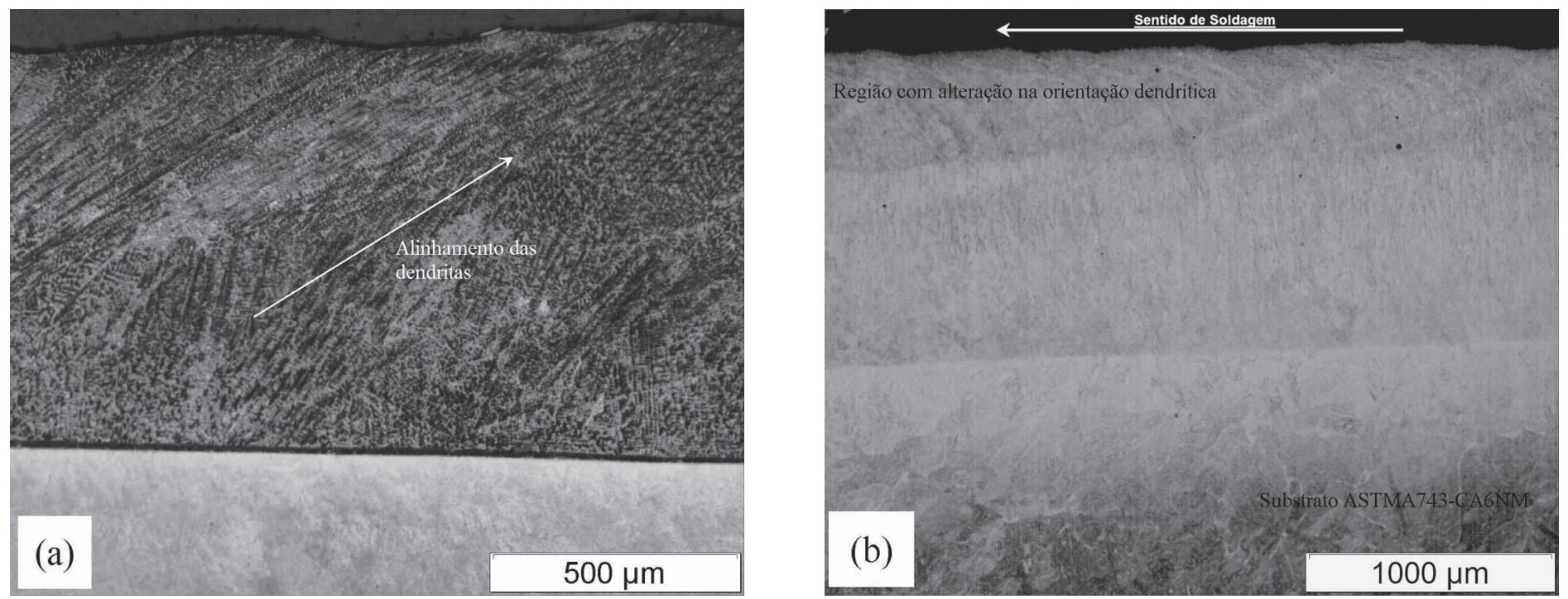

Figura 4. Micrografia das amostras após refusão, corte longitudinal, (a)130A e (b)180-80A. 

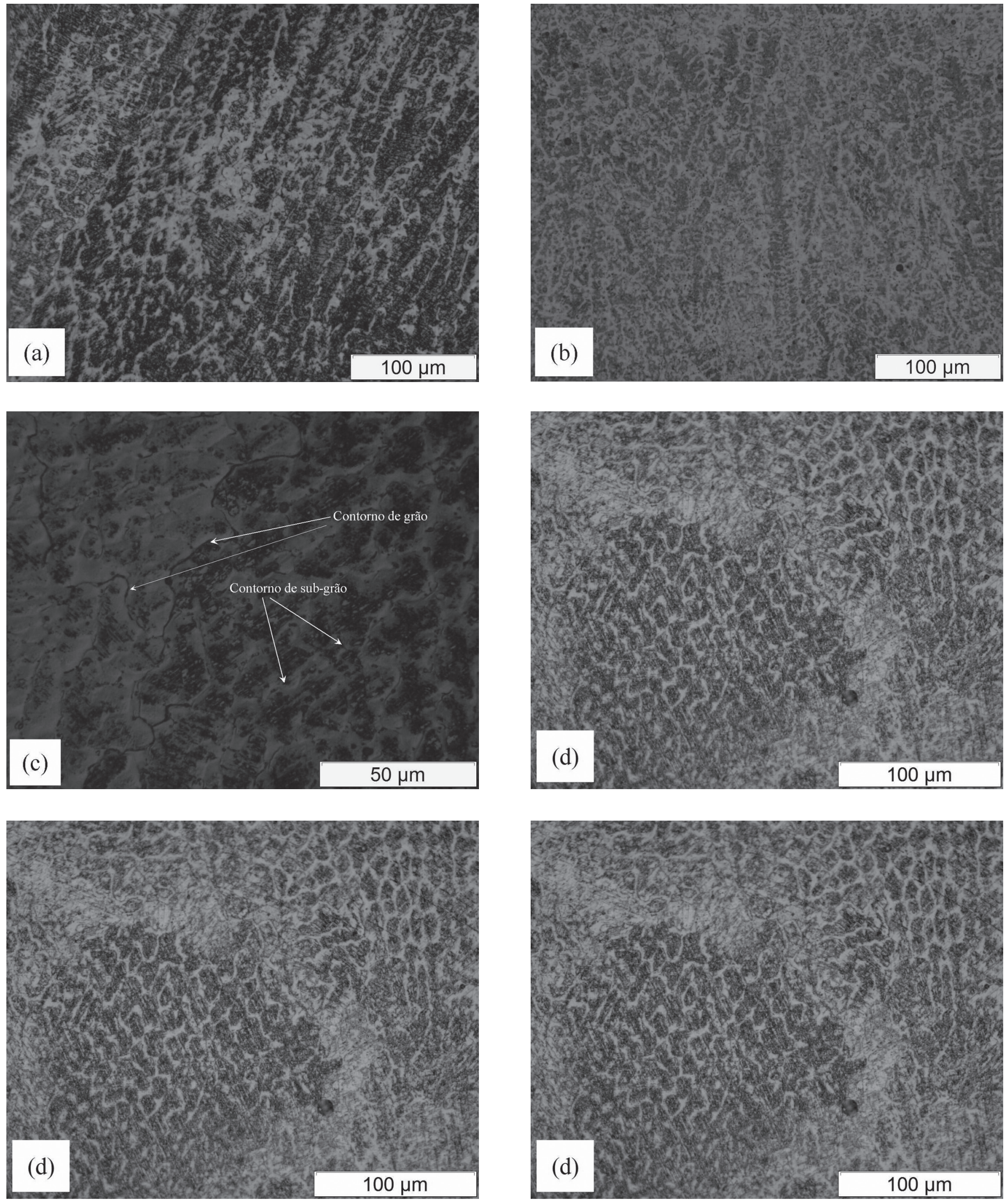

Figura 5. Formação de estrutura martensítica e dendritas de solidificação das amostras refundidas, (a, c, e) 90A, 110A e 130A, (b, d, f) $100-80 \mathrm{~A}, 140-80 \mathrm{~A}$ e $180-80 \mathrm{~A}$, respectivamente, reativo Vilella. 
80A. Devido a maior agitação da poça fundida, promovida pela utilização da corrente pulsada, houve quebra no crescimento das dendritas durante o pulso de base, e consequente alteração no sentido de crescimento destas, como pode ser observada na diferença de orientação entre a região superior e inferior do revestimento visualizado na Figura 4(b) $[22,23]$. A espessura da região reorientada nas amostras refundidas com corrente pulsada de $140-80$ e $180-80$ A foi de aproximadamente $500 \mu \mathrm{m}$.

$\mathrm{Na}$ Figura 5 é visualizado em detalhes a microestrutura da região próxima à superfície dos revestimentos refundidos, observa-se na Figura 5(a) o alinhamento das dendritas em relação à movimentação da tocha, bem como a formação de contornos de grão e sub-grão Figura 5(c). Também pode ser visualizado a formação de martensita dentro dos limites do subgrão na Figura 5(e)

A formação da martensita ocorre dentro dos limites de solidificação dos sub-grãos dentro das dendritas de solidificação, como pode ser observado na imagem obtida por MEV ilustrada na Figura 6. A formação de martensita é observada pela presença de finas agulhas paralelas, no caso da martensita $\varepsilon$, enquanto que a martensita $\alpha$ ' apresenta-se na forma de placas mais espessas $[25,26]$. Não é possível diferenciar de forma clara o tipo de martensita formada, porém os revestimentos depositados foram avaliados por DRX, confirmando a presença de austenita $\gamma$ como fase majoritária e certa quantidade de martensita $\alpha$ e martensita $\varepsilon$.

A formação de martensita dentro destes limites provavelmente ocorra devido à redistribuição de soluto durante a solidificação, entretanto análises de EDX não identificaram diferenças significativas de composição química entre estas regiões. A formação de martensita $\varepsilon$ é provável nestas ligas devido a baixa energia de falha de empilhamento encontrada nesta liga, em decorrência da adição de Si e Mn [27].

Na Figura 7 é visualizado o perfil de composição química das amostras com menor corrente de refusão, 90A e 100-80A, e as duas últimas, referente as amostras com maior corrente, 130A e 180-80A. Pode-se observar uma redução nos níveis de $\mathrm{Mn}$ e Si nas amostras refundidas com 180-80A e 130A,

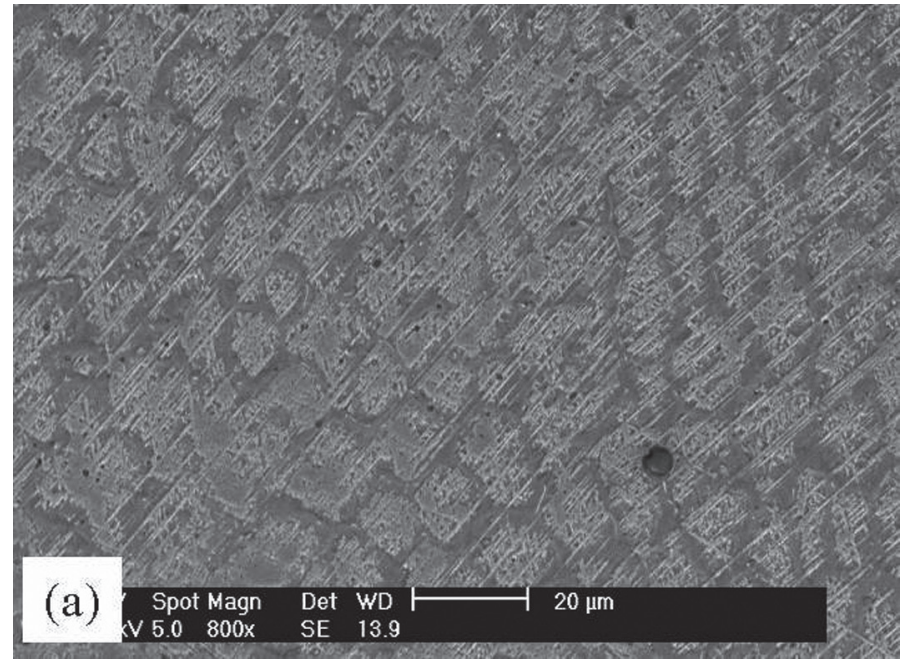

em relação às amostras refundidas com menores aportes térmicos. É verificado também uma maior redução de Mn na amostra refundida com corrente pulsada $180-80 \mathrm{~A}$ em relação à amostra refundida com corrente contínua e mesmo valor de corrente média, 130A, provavelmente em virtude da maior penetração observada. Paralelamente verifica-se maior teor de $\mathrm{Ni}$ nas amostras refundidas com 130 e 180-80A, em decorrência da maior diluição do metal base. Apesar das alterações de composição química com a diluição, não foram observadas alterações significativas na microestrutura, observada por DRX e MEV, dos revestimentos avaliados.

Os perfis de microdureza dos revestimentos refundidos apresentaram-se pouco susceptíveis às alterações na intensidade e tipo de corrente utilizados, onde os valores encontrados nas amostras ficaram muito semelhantes, Figura 8. Este fato pode ser decorrente da proximidade dos de valores de $\mathrm{Cr}_{\text {eq }}$ e $\mathrm{Ni}_{\text {eq }}$ do revestimento 11 e 8 , respectivamente, e metal base 13 e 5 , calculados a partir a composição química por EDX e utilizandose as equações do Diagrama de Schaeffler. Estes valores indicam a presença de martensita para o metal base e da forrmação de austenita e martensita para uma ampla faixa de diluição. A alteração na formação dendrítica com a utilização de corrente pulsada foi avaliada, entretanto nenhuma alteração significativa nos valores de microdureza foi observada.

Apesar do perfil de microdureza do revestimento ser pouco dependente dos parâmetros de refusão, a intensidade de corrente e o tipo de corrente empregados alteraram significativamente o perfil de microdureza da ZTA do aço ASTM-A743-CA6NM. É possível observar menores valores de dureza da ZTA nas regiões mais próximas da linha de fusão, regiões em que ocorre a formação de ferrita $\delta$ primária e bifásica, em relação às regiões monofásica austenítica e bifásica de baixa temperatura. A formação de martensita na região aquecida no campo monofásico, a partir da transformação parcial da austenita em martensita produz uma elevação no valor de dureza. Resultados similares obtidos em aços supermartensíticos de composição

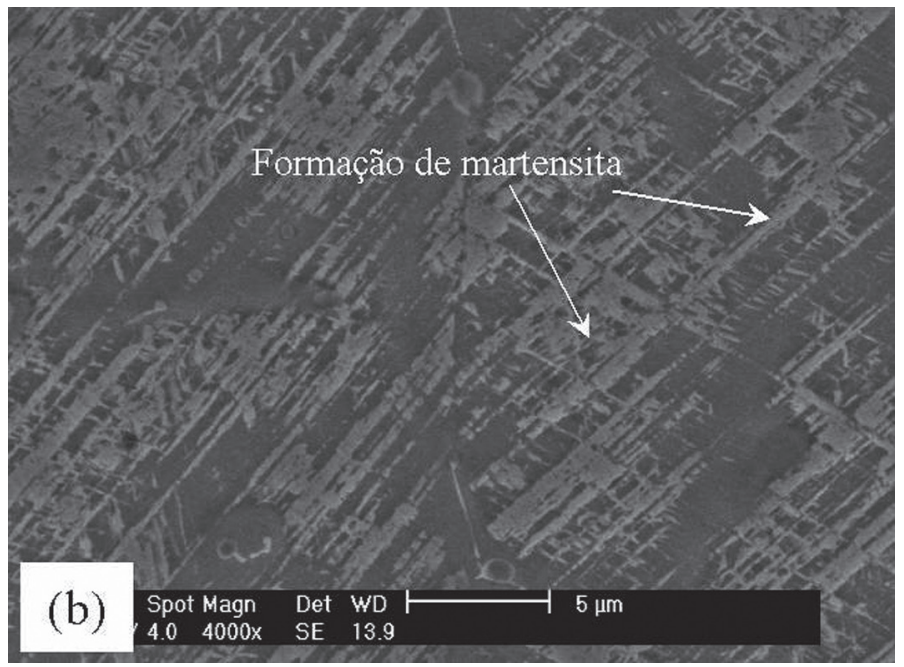

Figura 6. Detalhe da formação da martensita dentro dos sub-grãos dentro das dendritas de solidificação: (a) dendrita 180-80A, (b) 180-80A, formação da martensita no sub-grão, reativo Vilella. 
(a)
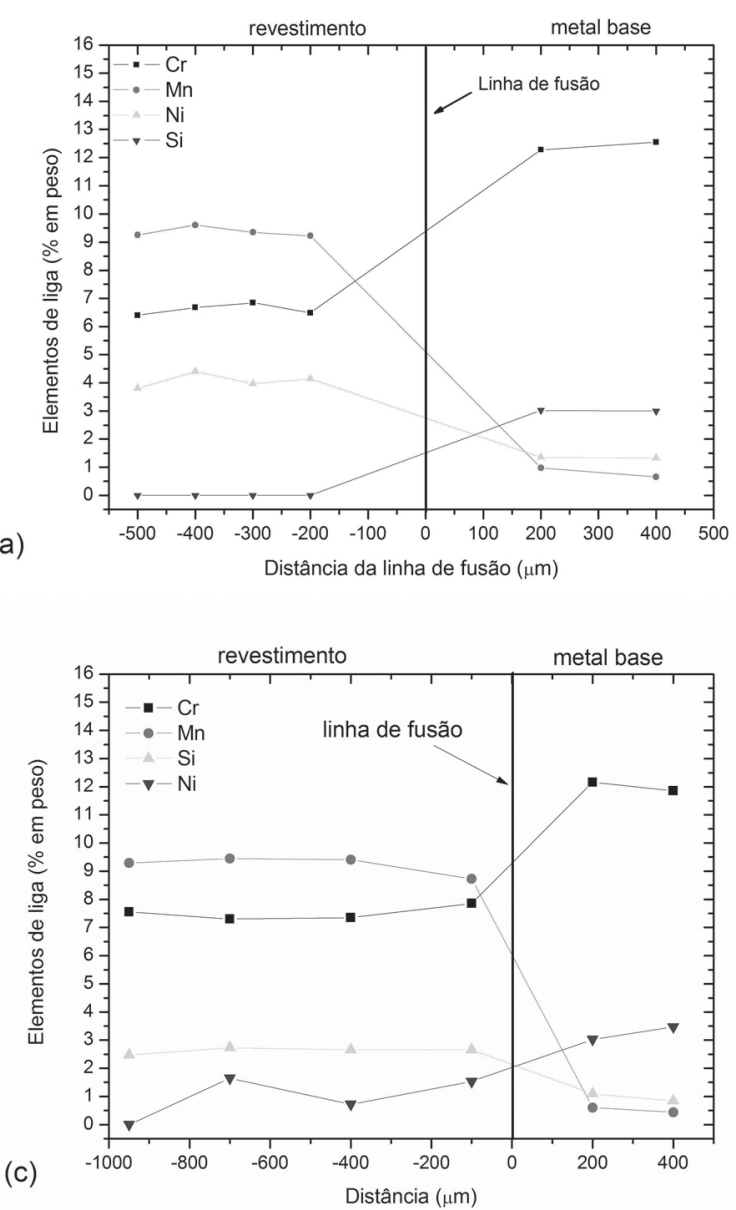
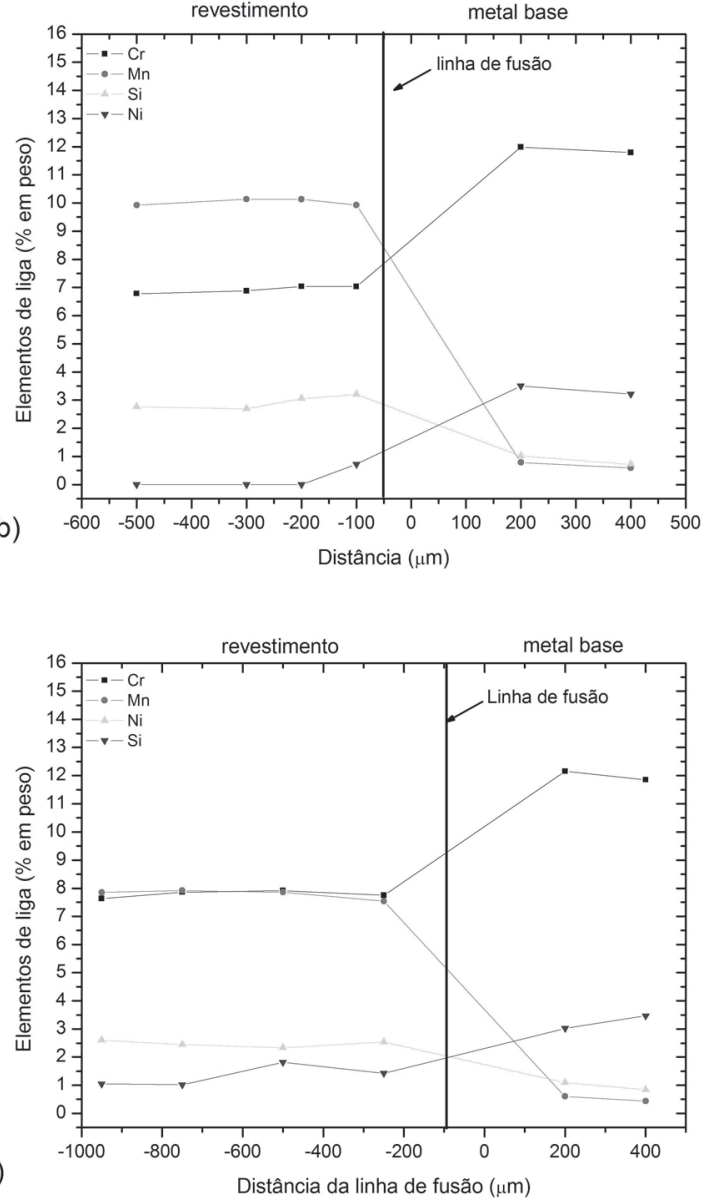

Figura 7. Perfil de composição química dos revestimentos refundidos por PTA (a) 90A, (b) 100-80A, (c) 130A e (d) 180-80A.

semelhante foram observados em trabalhos anteriores com soldagem TIG (tungsten inert gas) e Plasma PTA $[12,13,28]$.

Observa-se que as amostras refundidas com corrente pulsada apresentaram redução na largura da ZTA em relação às amostras refundidas com corrente contínua constante de mesmo aporte térmico, efeito mais acentuado nas amostras refundidas com maior aporte térmico. Maior largura da ZTA com a utilização de corrente contínua constante foi observada em outra pesquisa utilizando material base semelhante, sendo que a maior largura da ZTA foi atribuído ao maior tempo de permanência acima de AC1 para esta condição de refusão [29].

Adicionalmente ao reativo Vilella utilizou-se um ataque químico eletrolítico, contendo ácido sulfúrico, com a intenção de se analisar a formação de Ferrita $\delta$ na ZTA das amostras refundidas com diferentes valores de corrente. Através da adoção deste reativo é possível correlacionar a microestrutura formada com a temperatura de pico desta região, pois a formação de martensita $\delta$ ocorre no aço CA6NM em temperaturas entre 1450 e $1300^{\circ} \mathrm{C}$ e a região de estrutura bifásica, ferrita $\delta$ e austenita $\gamma$, ocorre entre 1300 e $1200^{\circ} \mathrm{C}$ aproximadamente [12].

As microestruturas das amostras observadas após ataque químico eletrolítico podem ser visualizadas na Figura 9, onde se constata que as amostras refundidas com valores mais baixos de corrente, 90 e 100-80A, promoveram a formação de ferrita $\delta$ somente no campo bifásico. As amostras refundidas com valores mais elevados de corrente apresentaram a formação de ferrita $\delta$ a elevadas temperaturas no campo primário e no campo bifásico.

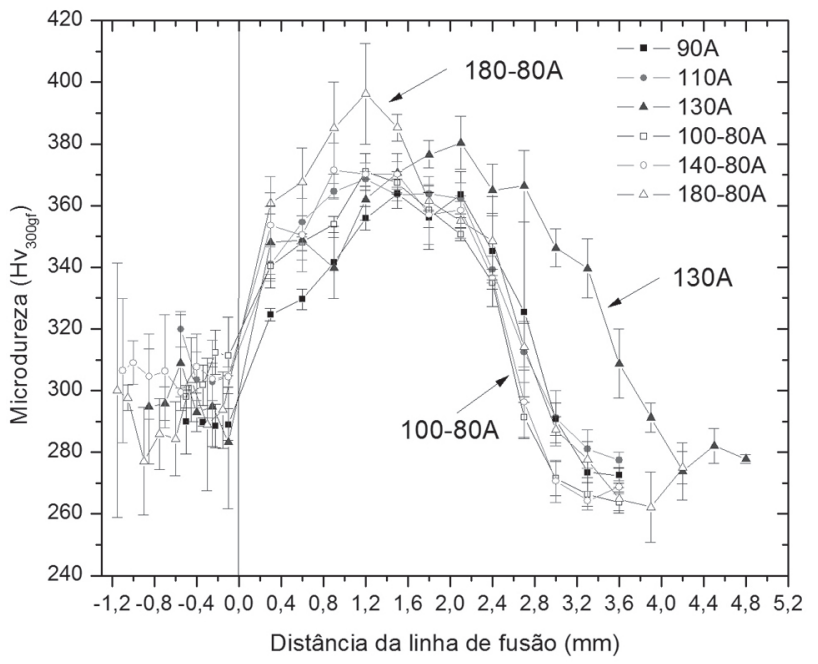

Figura 8. Perfil de Microdureza das amostras refundidas. 

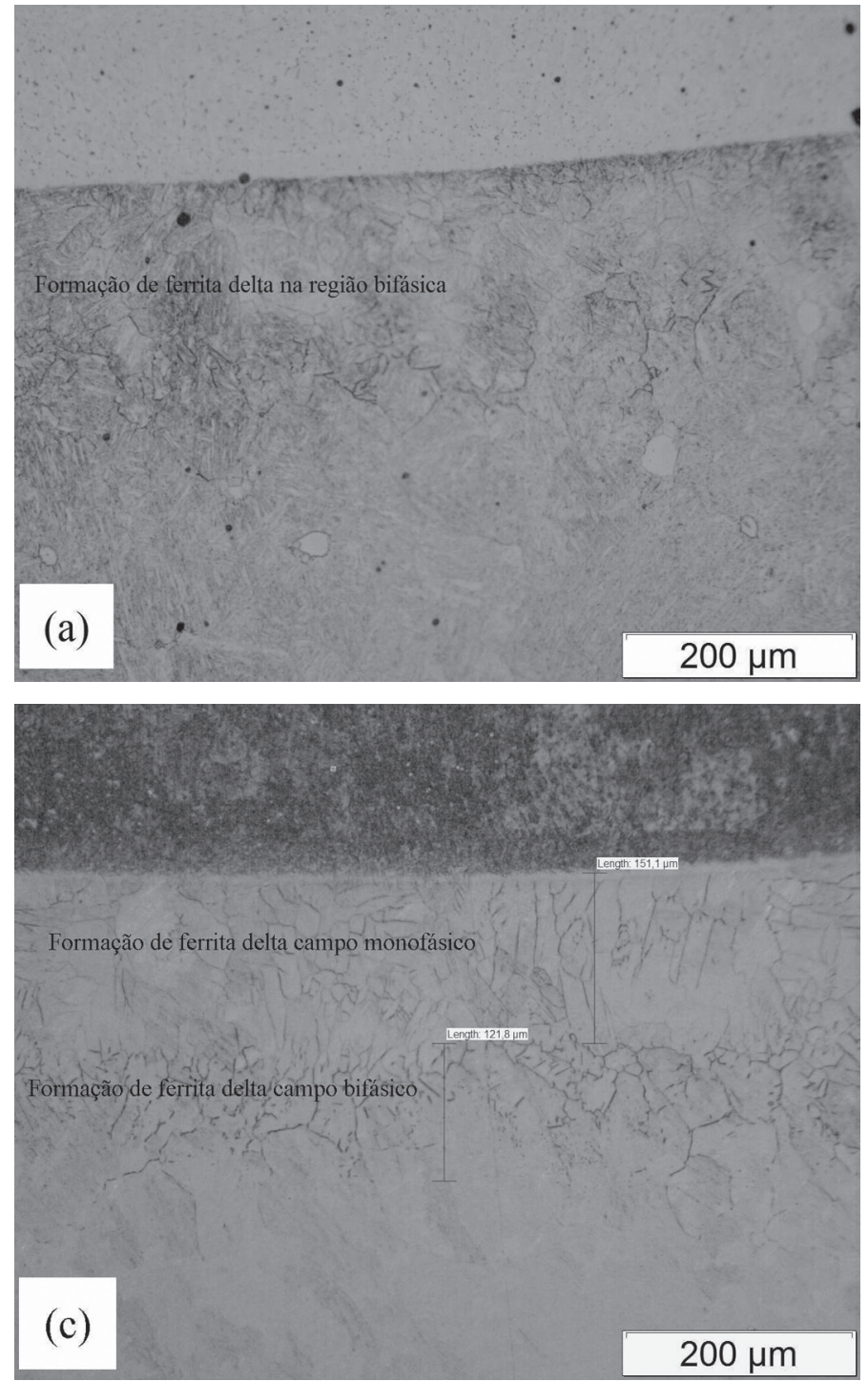
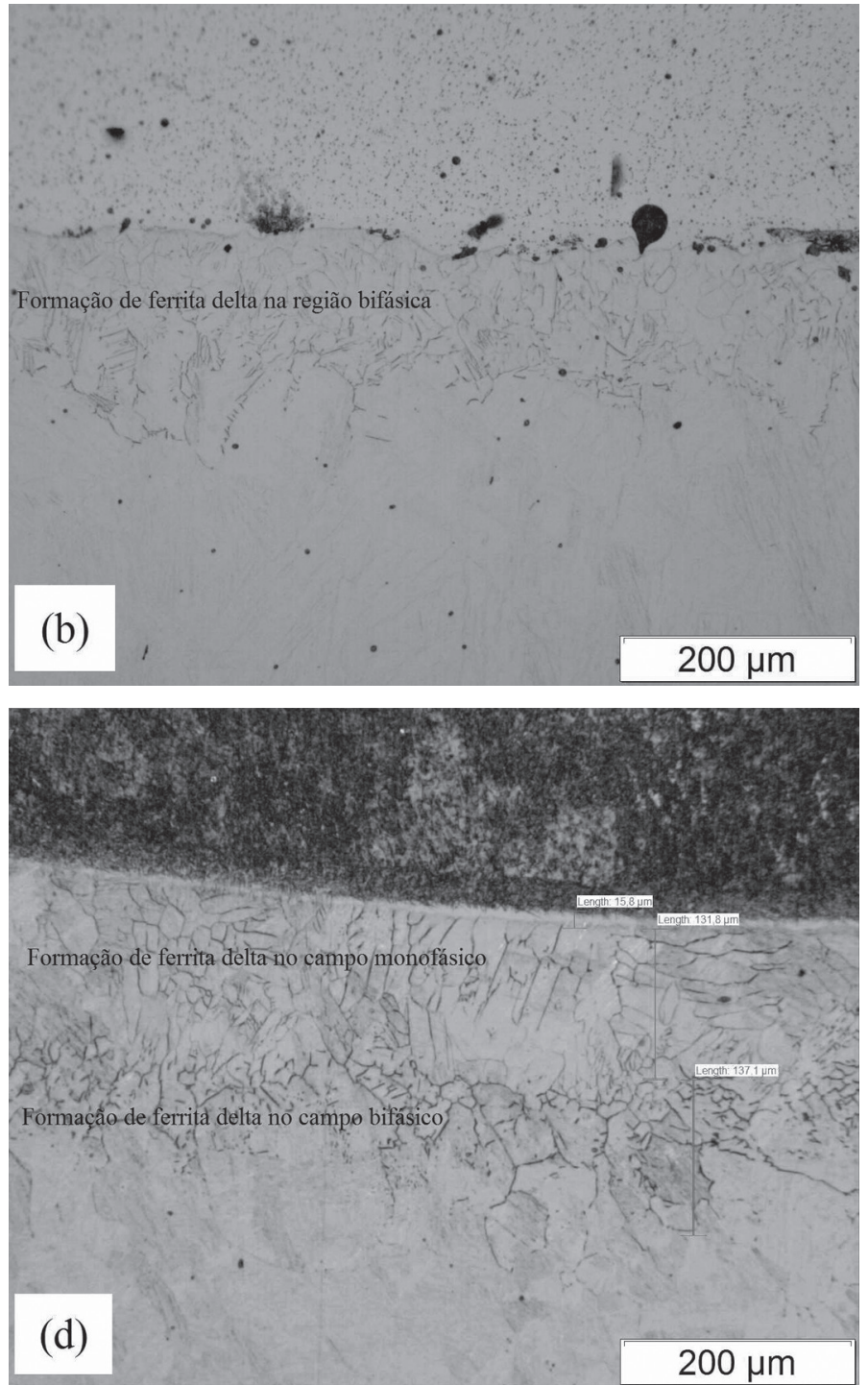

Figura 9. Formação de ferrita $\delta$ na ZTA nas amostras refundidas, (a, c) 90A, e 130A, (b, d)100-80A e 180-80A, respectivamente, reativo ácido sulfúrico eletrolítico.

A pequena diluição e a não formação de ferrita $\delta$ primária nas amostras refundidas com menores valores de corrente e a formação de estrutura do tipo ferrita $\delta$, no campo monofásico e no campo bifásico, devido aos maiores valores de temperatura de pico obtidas nas amostras refundidas com maiores valores de corrente.

A análise dos ciclos térmicos realizada nas amostras durante a refusão indicou que a temperatura de pico a $3 \mathrm{~mm}$ da linha de fusão para as amostras refundidas com corrente contínua, variaram entre 855 e $480^{\circ} \mathrm{C}$, respectivamente, enquanto que para as amostras com corrente pulsada as temperaturas de pico a $3 \mathrm{~mm}$ da superfície revestida variaram de 825 a $480^{\circ} \mathrm{C}$ -

Em relação à diferença de temperatura de pico entre as amostras deve-se avaliar que as amostras refundidas com 130, 140-80 e 180-80A tiveram penetração no metal base, sendo que a distância da linha de fusão até o termopar para estas amostras foi de $2,7 \mathrm{~mm}, 2,8 \mathrm{~mm}$ e 2,2 $\mathrm{mm}$, respectivamente. Portanto as isotermas avaliadas são diferentes das avaliadas nas amostras com 90,110 e 100-80A.
Para as amostras 110 e 130A observa-se uma aumento na temperatura de pico, para os termopares localizados a $3 \mathrm{~mm}$ da linha de fusão, em comparação com as amostras refundidas com corrente pulsada e mesmo valor de corrente média. Resultados semelhantes são descritos na literatura, onde medições de espessura da região monofásica de ferrita $\delta$, indicaram que amostras refundidas com corrente contínua constante apresentaram espessura maior que amostras utilizando corrente pulsada e mesmo aporte térmico [29].

Comparando-se as temperaturas de pico a diferentes distâncias da superfície refundida observa-se o aumento da distância da linha de fusão acarreta uma diminuição na temperatura. A temperatura de pico das amostras refundidas com corrente pulsada e corrente contínua torna-se mais semelhante a medida que aumenta a distância da linha de fusão, Figura 10.

Este comportamento é muito próximo do observado na avaliação da microdureza, onde se verificou uma maior largura da ZTA com o aumento da intensidade de corrente e com o uso de corrente contínua. A maior dureza e o menor comprimento 
(a)

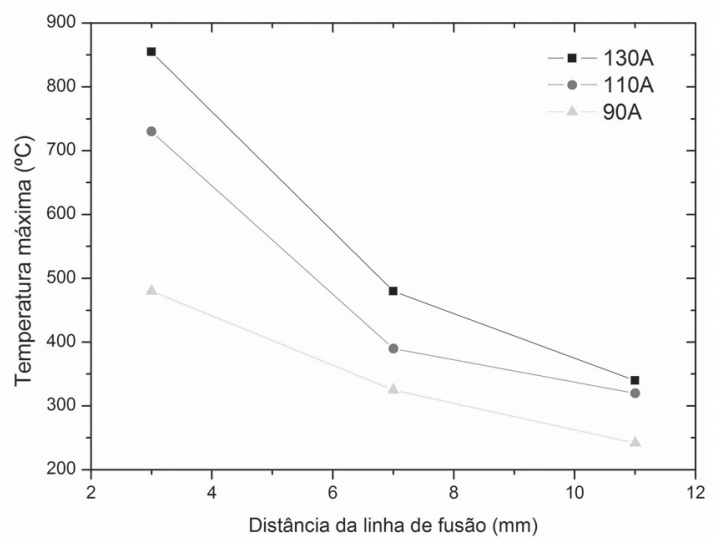

(b)

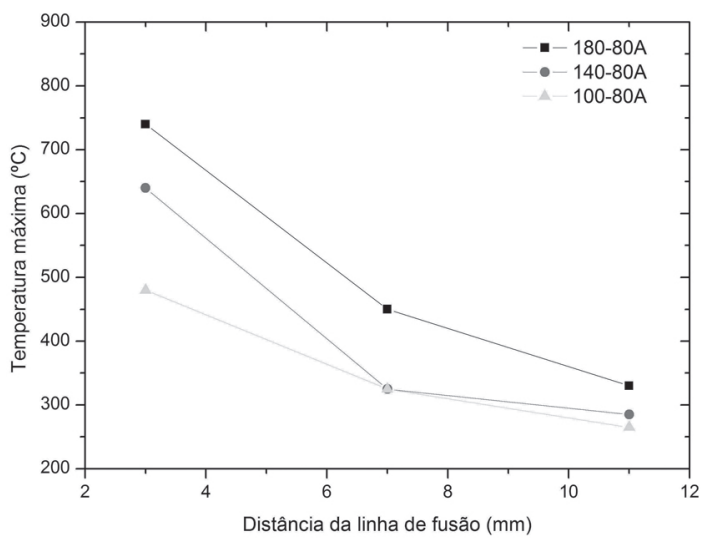

Figura 10. Variação na temperatura de pico das amostras refundidas com a distância da superfície refundida: (a) corrente contínua, (b) corrente pulsada.

da ZTA nas amostras com corrente pulsada, pode ser explicado pela maior taxa de resfriamento observado para este tipo de corrente. A menor temperatura de pico, aliado a uma maior taxa de resfriamento nesta região tende a gerar um refino de grão e um maior teor de martensita, elevando assim a dureza desta região da ZTA das amostras refundidas com corrente pulsada.

\section{Conclusões}

Após o estudo do tipo e intensidade de corrente na refusão de uma liga resistentes a cavitação Fe-Mn-Cr-Si depositada por aspersão térmica, nas condições avaliadas, foi possível concluir que:

- Foi possível obter um revestimento isento de poros e óxidos a partir do processo de refusão por plasma de um revestimento previamente aspergido. Foi observado que tanto a microestrutura quanto a microdureza não apresentaram variações significativas em suas propriedades com a alteração do tipo e intensidade de corrente utilizadas

- Os revestimentos obtidos por deposição a arco elétrico, seguido de refusão por plasma PTA, utilizando corrente contínua constante, apresentaram um alinhamento da microestrutura no sentido da movimentação da tocha, sendo que a utilização de corrente pulsada promoveu uma redução neste alinhamento sem, entretanto, alterar a microdureza do revestimento.

- A variação no tipo de corrente e em sua intensidade apresentaram-se mais influentes na microestrutura e perfil de microdureza da ZTA do metal base, que na microestrutura e propriedades do revestimento. O aumento da intensidade de corrente, bem como a utilização de corrente contínua constante promoveu um aumento na espessura da região de formação de ferrita $\delta$ e na largura total da ZTA do aço CA6NM. Este resultado indica que a adoção de menores valores de corrente média permite a obtenção de revestimentos adequado, ou seja, isento de poros e óxidos, com menor influência nas propriedades do metal base.

- Observou-se que a ZTA das amostras refundidas com corrente pulsada apresentaram uma menor largura total, em comparação com amostras refundidas com corrente contínua constante e mesmo valor de corrente média. Estes resultados foram confirmados com às medições de ciclos térmicos realizadas, onde se observou maiores temperaturas de pico para as amostras refundidas com corrente contínua constante que para as amostras obtidas com corrente pulsada.

\section{Agradecimentos}

Os autores agradecem a Fundação Araucária pelo suporte financeiro, edital Programa Primeiros Projetos 013/2009, a Voith Hydro pelo envio do metal base CA6NM, a DURUM pela fabricação do arames, ao Lactec e UFPR pela utilização dos laboratórios de soldagem e Aspersão e ao Prof. Dr. Sérgio Henke pelo auxílio na execução dos ataques eletrolíticos.

\section{Referências Bibliográficas}

[1] HUTH, HANS-JÖRG, Fatigue design of hydraulic turbine runners, 2005, 178p., Tese (Doutorado) - Department of Engineering Design and Materials, Norwegian University of Science and Technology, Trondheim, Norway.

[2] BOCCANERA, L., et al., Cavitation erosion resistanse of Co-alloyed stainless steel weld cladding as compared to termal sprayed coatings, Anais do XXV Encontro Nacional de Tecnologia da Soldagem, Belo Horizonte - Brasil, 08-10 set. 1999.

[3] AKHTAR, A., Materials technology for turbine performance, Water Power \& Dam Construction, v.38, n.8, p. 13-19, ago. 1996.

[4] CHANG, J.T., et al., Cavitation erosion and corrosion behavior of Ni-Al intermetallic coatings, Wear, v. 255, p.162169, ago/set. 2003.

[5] CHANG, S.C., et al., The cavitation erosion of Fe-Mn-Al alloys, Wear, v. 181-183, p.511-515, mar. 1995.

[6] WANG, Z., ZHU, J., Effect of phase transformation on cavitation erosion resistance of some ferrous alloys, Materials 
Science and Engineering A, v.358, n. 1-2, p.273-278, out. 2003. [7] STELLA, J., et al., Cavitation erosion of plasma-sprayed NiTi coatings, Wear, v. 260, no 9-10, p. 1020-1027, mai. 2006.

[8] CHIU, K.Y., CHENG, F.T., MAN, H.C., Laser cladding of austenitic stainless steel using NiTi strips for resisting cavitation erosion, Materials Science and Engineering A, v.402, n.1-2, p.126-134, ago. 2005.

[9] CUI, Z.D., et al., Cavitation erosion-corrosion characteristics of laser surface modified NiTi shape memory alloy, Surface \& Coatings Technology, v.162, n.2-3, p.147-153, jan. 2003.

[10] WU, S.K., LIN, H.C., YEH, C.H., A comparasion of the cavitation erosion resistance of TiNi alloys, SUS304 stainless steel and Ni-based self fluxing alloy, Wear, v. 244, n.1-2, p.85-93, ago. 2000.

[11] KWOK, C.T., MAN, H.C., CHENG, F.T., Cavitation erosion-corrosion behavior of laser surface alloyed AISI1050 mild steel using $\mathrm{NiCrSiB}$, Materials Science and Engineering A, v.303, n.1-2, p.250-261, maio 2001.

[12] CARRouge, D., Phase transformations in the heataffected zone of low carbon $13 \% \mathrm{Cr}$ stainless steels, 2002, 185p., Tese (Doutorado), Materials Science and Metallurgy Department, Cambridge University.

[13] ENERHAUG, J., GRONG, O., STEINSMO, U.M., Factors affecting initiation of pitting corrosion in super martensitic stainless steel weldments, Science and Technology of Welding and Joining, v.6, n.5, p.330-338, out. 2001.

[14] BOY, J. H. et al, Cavitation and Erosion Resistant Thermal Spray Coatings, Construction Productivity Advancement Research (CPAR) PROGRAM, Technical Report no 97/118, Exército EUA, jul. 1997, 146p.

[15] NEWBERY, A.,P., GRANT, P.S., NEISER, R.A., The velocity and temperature of steel droplets during eletric arc spraying, Surface \& Coating Technology, v.195, n.1, p.91-101, maio 2005 .

[16] DESHPANDE, S., SAMPATH, S., ZHANG, H., Mechanisms of oxidation and its role in microstructural evolution of metallic thermal spray coatings - Case study for Ni-Al, Surface \& Coatings Technology, v.200, n 18-19, p.5395-5406, maio 2006.

[17] LIMA, M.M., et al., Coating fracture toughness determined by Vickers indentation: an important parameter in cavitation erosion resistance of WC-Co thermally sprayed coatings, Surface \& Coatings Technology, v.177-178, p.489-496, jan.2004.

[18] YUPING, W., et al., Cavitation erosion characteristics of a $\mathrm{Fe}-\mathrm{Cr}-\mathrm{Si}-\mathrm{B}-\mathrm{Mn}$ coating fabricated by high velocity oxy-fuel (HVOF) thermal spray, Materials Letter, v.61, n.8-9, p.18671872, abril 2007.

[19] GIREŃ, B.G., SZKODO, M., STELlER J., Cavitation erosion of some laser produced iron base corrosion resistant alloys, Wear, v.258, p.614-622, jan. 2005.

[20] MITELEA, ION et al., Cavitation resistance coatings deposited on titanium alloys substrates by plasma spraying and electron beam remelting, METAL2010, International Conference on Metallurgy and Materials, 18-20 de maio de 2010, Roznov pod Radhostem, República Tcheca, 2010.

[21] HIRAGA, H., et al., Cavitation erosion mechanism of NiTi coatings made by laser plasma hybrid spraying, Wear, v.231, n.2, p.272-278, jul.1999.
[22] SOLOMON, H.D., Fundamentals of weld solidification: Welding, Brazing and Soldering, Metals Handbook,ASM International, v.6, Ohio, 1993, 110-135.

[23] BOND, DANIELLE, Avaliação de revestimentos soldados processados com materiais atomizados, 2008, 133p., Tese (Doutorado), Programa de Pós-Graduação em Engenharia, UFPR, Curitiba, Paraná, Brasil.

[24] BOND, D., BECKER, S., F., D’OLIVEIRA, A., S., C., Influência da corrente e granulometria do material de adição nos revestimentos processados por PTA, Soldagem \& Inspeção, v.16, n1, p.53-61, Jan/Mar2011.

[25] BERGEON, N., GUENIN,G., ESNOUF, C., Characterization of the stress-induced o martensite in a $\mathrm{Fe}-\mathrm{Mn}-$ $\mathrm{Si}-\mathrm{Cr}-\mathrm{Ni}$ shape memory alloy: microstructural observation at different scales, mechanism of formation and growth, Materials Science and Engineering A, v.238, n.2, p.309-316, abr.1997.

[26] NASCIMENTO, F.,C., et al., Stainless steel shape memory alloys microstructure analysis by optical microscopy using different etchants, Acta Microscopica, v.12, n.1, p.99102, dez. 2003.

[27] OTSUKA, H., et al., Effects of alloying aditions on FeMn-Si Shape memory alloys, ISIJ International, v. 30, n.8, p. 674-679, dez.1990.

[28] WOOLlin, P., CARROUGE, D., Heat affected zone microstructures in supermartensitic stainless steels, Conference on Super martensitic Stainless Steels, Bruxelas, Bélgica, 3 a 4 de outubro de 2002.

[29] HENKE, S. L., Efeito da soldagem plasma pulsada na microestrutura e resistência à fadiga de um aço inoxidável supermartensítico, 2010, 120p., Tese (Doutorado), Programa de Pós Graduação em Engenharia Mecânica, UFPR, Curitiba, Paraná, Brasil. 